\title{
Physical-Chemical Parameters And Phenolic Compounds From Fetească Neagră Wines Aged In Different Toasted Barrels
}

\author{
Georgiana-Diana DUMITRIU ${ }^{1 *)}$, Valeriu V. COTEA ${ }^{1)}$, Rafael Amores PEINADO ${ }^{2)}$, \\ Nieves LOPEZ DE LER-MA ${ }^{2)}$, Cătălin ZAMFIR ${ }^{1)}$, Marius NICULAUA ${ }^{11}$, Bogdan NECHITA ${ }^{11}$, \\ Cintia COLIBABA ${ }^{1)}$, Ioan MORARU ${ }^{1)}$, Maria CODREANU ${ }^{1)}$, Florin VARARU ${ }^{1)}$ \\ 1) Faculty of Horticulture, University of Agricultural Sciences and Veterinary Medicine "Ion Ionescu de \\ la Brad" Iasi, Romania. \\ ${ }^{2}$ Agricultural Chemistry Department.University of Cordoba, Spain. \\ ${ }^{*}$ Coresponding author, e-mail: dumitriu.diana22@yahoo.com
}

Bulletin UASVM Horticulture 71(2) / 2014

Print ISSN 1843-5254, Electronic ISSN 1843-5394

DOI:10.15835/buasvmcn-hort:10294

\begin{abstract}
The goal of this study is to evaluate the influence of toasted barrel on the red wines physical-chemical parameters and phenolic compounds. Experimental material used is Fetească neagră grapes. They were harvested from Şuletea wine region-Vaslui, in 2013. The wines content of phenolic compounds varied, depending on the toasted barrel variant (V0-martor wine, V1-barrel light, V2-barrel medium and V3-barrel medium plus). In order to characterize phenolic compounds we have realized a series of spectrometric measurements to evaluate the total polyphenolic index and total anthocyans by $\mathrm{pH}$ variation method. Martor wine (V0) showed higher phenolic compound values than samples in toasted barrels. This fact indicates that the toasting process of barrels reduces the phenolic compounds present in wines. Also, we observed decrease of values for anthocyans caused by the increase in intensity of toasted process. The structural characteristics of wood and its chemical composition can influence the complex physical, chemical and biochemical processes that take place during the oxidative ageing of wine in barrels.
\end{abstract}

Keywords: anthocyans, barrels, Fetească neagră, phenolic compounds.

\section{INTRODUCTION}

Ageing of wine in wood barrels is a key step in winemaking, promotes changes in colour, structure, and especially aroma, since different reactions occur among phenolic compounds, while several compounds are extracted from wood, increasing wine complexity and stability (FernándezdeSimónetal., 2009; Rosso etal., 2009). The enrichment of wine by compounds extracted from oak and the slow but continuous diffusion of atmospheric oxygen through wood pores (natural microoxygenation) are the main phenomena involved in the changes in wine quality induced by oak barrel maturation (oxidative aging) (Díaz-
Plaza et al., 2002; Escalona et al., 2002; Fulcrand et al., 2006; Garde-Cerdán and Ancín-Azpilicueta, 2006).

The structural characteristics of wood (grain, porosity, permeability) and its chemical composition (polyphenols, tannins, volatile compounds) can influence the complex physical, chemical and biochemical processes that take place during the oxidative ageing of wine in barrels, affecting their composition and organoleptic properties, and contributing to their stability (Garde-Cerdan et al., 2010; Puech et al., 1999). The barrel is usually chosen depending on wood origin and the processes used in its manufacturing, e.g. 
seasoning and toasting (Chatonnet et al., 1999; Doussot et al., 2002). The toasting process is a important practice that causes changes in the chemical composition of oak wood, which affects the antioxidant capacity.

Oxidative ageing leads to high quality wines, with enhanced organoleptic characteristics (including improvement of mouthfeel complexity, reduction of astringency and aroma enrichment) and more stable colour (De Beer et al., 2008).

Phenolic compounds are one of the most important quality parameters of wines, since they contribute directly or indirectly to wine organoleptic characteristics such as colour, astringency and bitterness and they are also involved in browning reactions in both grapes and wines (Macheix et al., 1991).

The polyphenolic profile variability of beverages, and their evolution during ageing, can make the analysis of markers found in the wood more complex. In wines, this variability can be attributed several factors, including some aspects of the raw material (grape variety, climatologic conditions, agronomic characteristics, degree of grape ripening) and winemaking process (time of maceration and fermentation in contact with the grape skins and seeds, pressing, fining, etc.) (Castillo-Muñoz et al., 2007; Monagas et al., 2005).

The total phenolic content of wines is therefore an important parameter of their antioxidant properties (Eberhardt et al., 2000; Wang et al., 1996). The usual determination of total polyphenolic content is achieved using the Folin-Ciocâlteu procedure of Singleton. This method is based on the chemical oxidation of the reduced molecules by a mixture of the two strong inorganic oxidants phosphotungstic and phosphomolybdic acids. In comparison with Folin, the enzymatic method offers the advantages of a briefer measuring period, a greater specificity toward the polyphenols, and the almost total absence of the common interferences.

The goal of this study is to evaluate the influence of toasted barrel on the red wines physicalchemical parameters and phenolic compounds.

\section{MATERIALS AND METHODS}

The wines analyzed were obtained from Fetească neagră varieties, harvested in 2013. The grape juice obtained was subjected to a maceration-fermentation process at temperature of $10-12^{\circ} \mathrm{C}$, for 7 days. In the next step, the marc was pressed and the wines obtained were transferred in fermentation tanks for the completing of alcoholic and malolactic fermentation. At the end of the fermentation processes, we divided in four variants the wines. The new samples used three types of new barrels (LT-barrel light toast, MTbarrel medium toast MT+- barrel medium plus toast).

Variation of phenolic compounds content depends on the barrel toasted variant (Tab.1).

Total acidity ( $\left.\mathrm{g} / \mathrm{L} \mathrm{C}_{4} \mathrm{H}_{6} \mathrm{O}_{6}\right), \mathrm{pH}$, volatile acidity (g/ $\mathrm{L} \mathrm{C}_{2} \mathrm{H}_{4} \mathrm{O}_{2}$ ) and alcohol strength (\% vol.) were analysed according to the methods proposed by O.I.V.(2013)(Fig. 1).

To characterize the phenolic compounds we used a spectrophotometric measurement, in order to evaluate the total quantity of anthocyans (at $280 \mathrm{~nm}$ ) and the total polyphenolic index of wines $(520 \mathrm{~nm})$. The total phenolic content was determined by the enzymatic method described by Stevanato, Fabris, and Momo (2004) and total anthocyans by $\mathrm{pH}$ variation method.

Data analyses were done with the statistical software package Statgraphics Centurion XVI from StatPoint Technologies, Inc. (Warrenton, VI, USA). A cluster analysis according to Ward's method was carried out by using the total polyphenolic index as classifying variables (Fig. 3).

Tab. 1. Experimental design a Fetească neagră wines

\begin{tabular}{lcc}
\hline Sample code designation & Produs type & Toasting level \\
\hline V0-Control & Without ageing & - \\
V1-Barrel LT & Barrel & Light Toast \\
V2-Barrel MT & Barrel & Medium Toast \\
V3-Barrel MT+ & Barrel & Medium Plus Toast \\
\hline
\end{tabular}



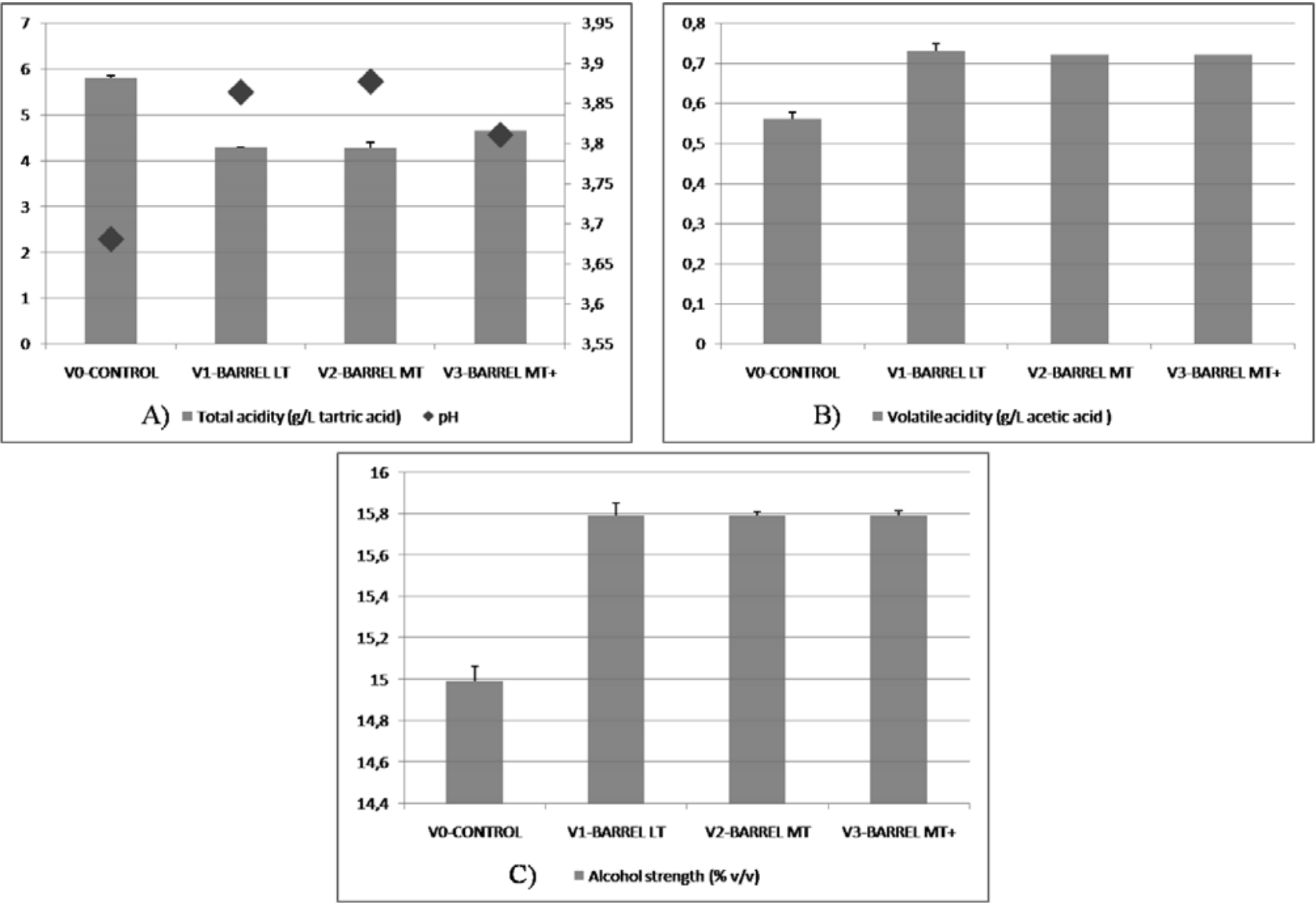

Fig. 1. Psysical-chemical parameters of red wines from Fetească neagră variety

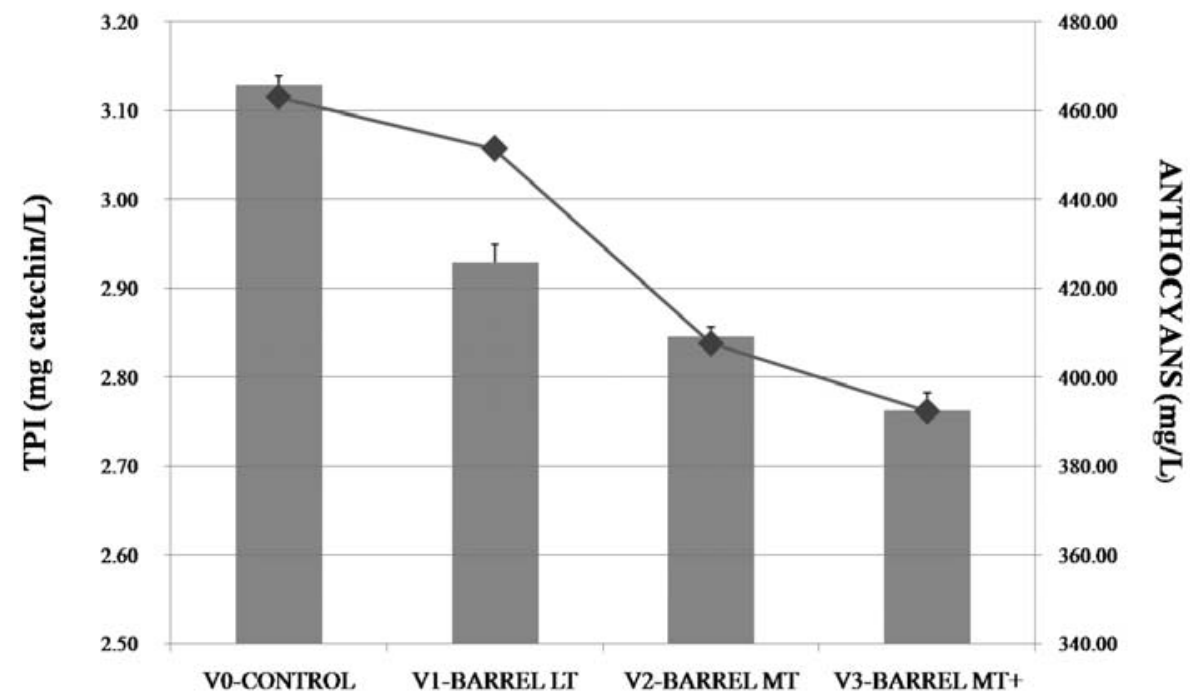

-TPI $($ mg catechin/L) $\rightarrow$ ANTHOCYANS $(\mathrm{mg} / \mathrm{L})$

Fig. 2. Total polyphenol index (mg catechin/L) and total quantity of anthocyans (mg/L) of Fetească neagră wines 


\section{RESULTS AND DISCUSSIONS}

The results of the conventional chemical analysis for variants of red wines aged in different barrels toasted at 1.5 months are illustrated in Fig 1 . The results are similar and within the usual values shown by red wines of the Romania NorthEast region.

In Fig.1A) we observe that V0-Control has a high values for the total acidity ( $\mathrm{g} / \mathrm{L}$ tartric acid) then all other samples. Also, the samples aged in barrels present values with a small variation, from 4.27 (g/L tartric acid)-V2 Barrel MT to 4.65 (g/L tartric acid)-V3 Barrel MT+. The decrease of total acidity in barrel samples can appear as a cause of metabolization of malic and citric acids or due to esterification fenomens, when a part of fixed acids combine with alcohols.

Volatile acidity (g/L acetic acid) increase in all types of barrels due mainly to the non-enzymatic oxidation process, when a very small part of ethyl alcohol was converted into acetaldehyde and then into acetic acid, the main component of volatile acidity (Cotea V.D. et al., 2009) Fig.1B).

It's noticed in fig.1C) a increase of the alcohol strength (vol. \%). Furthermore, the evaporation of water in a greater proportion than ethanol, as sometimes occurs when the wine is stored in wood barrels located in the dry atmosphere, can be an other cause of this difference. Red wines with a high alcohol strength perserve a longer time colours than wines with less alcohol.

During maturation occurs many processes that modify the composition and organoleptic characteristics of the wine. Among these processes (physical, chemical and biological) we remember: the dissolution of wood components barrel, condensation and deposition of phenolic compounds, modification of alcohol, aldehydes, acetals and esters contents and others.

The role of the barreles is important, since changes happen during the ageing process phenolic compounds solubilised from the wood improve the organoleptical caracteristics of wine; and a slow oxidation of some phenolic compounds by atmospheric oxygen, which passes through the wood pores results is a reduction of astringency and changes in the colour. Therefore, the organoleptic properties developed during the ageing process make the finished product highly valued.
In the category of phenolic compounds in wines may encounter: phenolic acids, anthocyanins, hydrolysable and unhydrolyzed tannins, volatile phenols and flavones. With the exception of hydrolysable tannins, which are derived mainly from the barrel stave, other phenolic compounds derived from grapes.

During maturation, phenolic compounds may participate in different reactions, although slow, however, they produce significant changes in wine. These reactions, besides the fact that the content itself causes significant variations in phenolic compounds wines, changes clarity of the precipitates that formed and influence at the same time and qualities of color and taste (Cotea V.D. et al., 2009).

All these phenomens finally lead to the impoverishment of wine phenolic compounds, including anthocyanins, which are reflected in changing hue, intensity reduction of red wines colour.

It should be underlined that the phenolic compounds are influenced by the presence of oxygen and acetaldehyde, condensation reactions, oxidation and precipitation. Moreover, there are other factors to be mentionated as: alcoholic strength, $\mathrm{pH}$, sulfur dioxide content, proteins, the presence of oxidation catalysts, etc.

In Fig. 2 is represented the total polyphenol index (mg catechin/L) and total quantity of anthocyans (mg/L) and can be observed that the maximum values of phenolic compounds and anthocyans is for V0-Control, $3.13 \mathrm{mg}$ catechin/L, respectively $463.04 \mathrm{mg} / \mathrm{L}$. In toasted barrels samples the phenolic compounds presence decrease in concordance with the increase of the toasting level. Also, quantity of anthocyans decrease, from $451.44 \mathrm{mg} / \mathrm{L}$ (V1-Barrel LT) to $392.37 \mathrm{mg} / \mathrm{L}(\mathrm{V} 3-$ Barrel MT+), due to condensation and copigmentation of phenolics compounds.

The total number of hydroxyl groups don't change much during direct and acetaldehydemediated condensation of anthocyanins with flavan-3-ols (Monagas et al., 2005).

The evolution and stabilisation of red wine colour during ageing is strongly associated with the complex reactions of anthocyanin copigmentation and condensation between anthocyanins and other phenolic compounds like flavan-3-ols (Timberlake and Bridle, 1976).

During the aging period of red wines several chemical reactions take place between phenolic 
compounds present in wine and those transferred from oak wood. These processes modify the phenolic compounds concentration and therefore, they also affect related parameters, especially that of anthocyans.

A higher content of dissolved oxygen has been reported for wine in new barrels than in used barrels (Castellari et al., 2004), which could increase the acetaldehyde content of the wine. New barrels also contain higher levels of hydrolysable tannins, which have a higher oxidising capacity than condensed tannins, leading to larger amounts of acetaldehyde being produced (Vivas and Glories, 1996).

A cluster analysis according to Ward's method was done by using total polyphenol index as classifying variables (Fig. 3). In this work, cluster analysis was used to assess the similarity between V0-Control and variants aged in different barrel toasted. This procedure has created one cluster from the 12 observations. It began with each observation in a separate group and combined them according to the distance between the groups. The distance at which the different groups were formed allowed us to discriminate sample control and sample aged for our three types of barrels. It's observed that group aged in barrel V1Barrel LT and V2-Barrel MT is really close to V3Barrel MT+.

\section{CONCLUSION}

The physico-chemical caracteristics of all the samples in toasted barrels have similar values, but for the V0-Control we observed a bigger value for total acidity and smaller values for alcohol and volatile acidity.

Red wines aged in barrels present a higher value in alcohol strength (vol.\%) that caused the preservation for a longer time of the colour compounds than wines with a lower alcohol strength.

The analyses showed that the V0-Control present the hightest values of phenolic compounds in comparison with samples aged in different toasted barrel. The increase of the toasting level determinats a quantitative decrease of phenolic compounds, from $2.92 \mathrm{mg}$ catechin/L (V1-Barrel LT) to $2.76 \mathrm{mg}$ catechin/L (V3-Barrel MT+). This case is also similar for the quantity of anthocyans from $451.44 \mathrm{mg} / \mathrm{L}$ (V1-Barrel LT) to 392.37 $\mathrm{mg} / \mathrm{L}$ (V3-Barrel MT+), due to condensation and copigmentation of phenolics compounds.

Statistical analyses realized by cluster analyses showed a difference between V0-Control and the samples aged in different toasted barrel (Light, Medium and Medium Plus) using the total polyphenolic index as classifying variables.

Acknowledgments. This paper was published under the frame of European Social Fund, Human Resources Development Operational Programme 2007-2013, projectno. POSDRU/159/1.5/S/132765. Wearegrateful toCampus deExcelencia Internacional Agroalimentario (ceiA3) and the International Doctoral Program of the University of Córdoba, in collaboration with Vitenol research Group

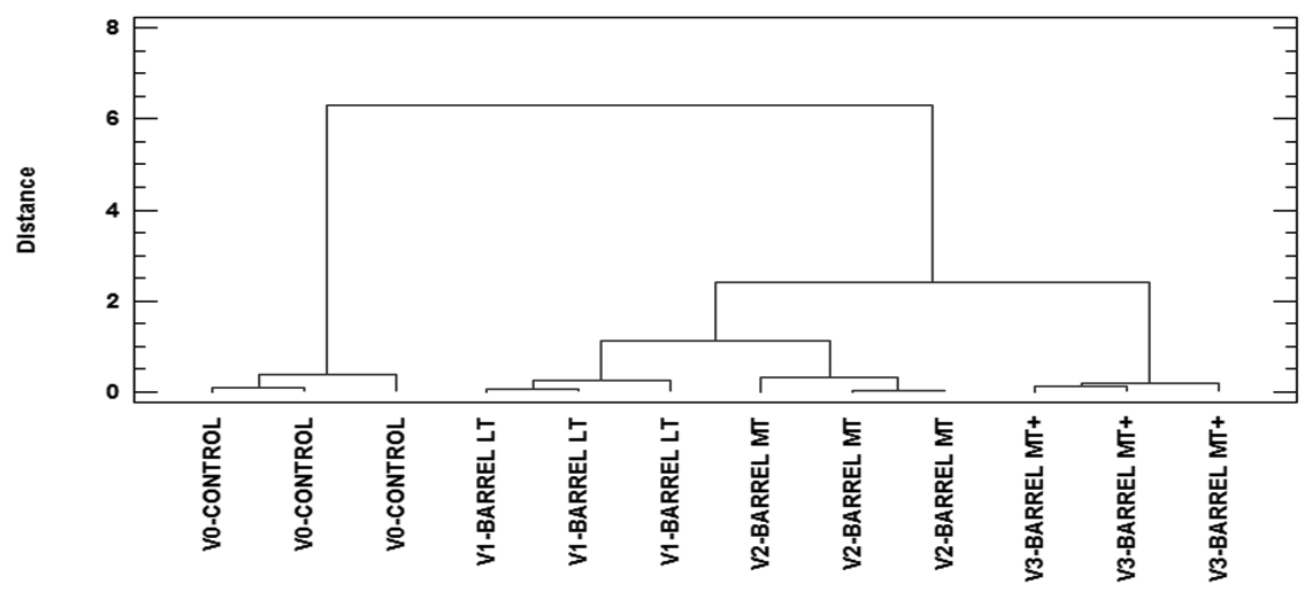

Fig. 3. Cluster analysis performed with Ward's method and total polyphenol index as classifying factors 


\section{REFERENCES}

1. Castellari M, Simonato B, Tornielli GB, Spinelli $\mathrm{P}$ and Ferrarini R (2004). Effects of different enological treatments on dissolved oxygen in wines. Ital. J.Food Sci. 16, 387-397.

2. Castillo-Muñoz N, Gómez S, Garacı and Herması I (2007). Flavonol profiles of Vitis vinifera L. red grapes and their single-cultivar wines. Journal of Agricultural and Food Chemistry, 55, 990-1002.

3. Chatonnet P, Cutzach I, Pons M and Dubourdieu D (1999). Monitoring toasting intensity of barrels by chromatographic analysis of volatile compounds from toasted oak wood. Journal of Agricultural and Food Chemistry, 47, 4310-4318.

4. Cotea VD, Zănoagă CV and Cotea VV (2009). Tratat de Oenochimie. Editura Academiei Române. București.

5. De Beer D, Joubert E, Marais J, Du Toit W, Fourie B and Manley M (2008).Characterisation of pinotage wine during maturation on different oak products South African. Journal of Enology and Viticulture, 29(1), 39-49.

6. 睢-Plaza EM , Reyero JR, Pardo F, Alonso GL and Salinas MR (2002). Influence of oak wood on the aromatic composition and quality of wines with different tannin contents. Journal of Agricultural and Food Chemistry, 50,2622-2626.

7. Doussot F, De Jeso B, Quideau S and Pardon P (2002). Extractives content in cooperage oak wood during natural seasoning and toasting: Influence of tree species, geographic location, and single-tree effects. Journal of Agricultural and Food Chemistry, 50, 5955-5961.

8. Escalona H, Birkmyre L, Piggott JR and Paterson A (2002). Effect of maturation in small oak casks on the volatility of red wine aroma compounds. Analytica Chimica Acta, 458, 45-54.

9. Fernandez de Simon B, Esteruelas E, Munoz AM, Cadahia E and Sanz M (2009). Volatile compounds in acacia, chestnut, cherry, ash, and oak woods, with a view to their use in cooperage. Journal of Agricultural and Food Chemistry, 57,3217-3227.

10. Fulcrand H, Dueñas M, Salas E and Cheynier V (2006). Phenolic reactions during winemaking and aging. American Journal of Enology and Viticulture, 57, 289-297.

11. Garde-Cerdán T and Ancín-Azpilicueta C (2006). Review of quality factors on wine ageing in oak barrels. Trends in Food Science and Technology, 17, 438-447.

12. Garde-Cerdan T, Lorenzo C, Carot JM, Esteve MD, Climent MD and Salinas MR (2010). Effects of composition, storage time, geographic origin and oak type on the accumulation of some volatile oak compounds and ethylphenols in wines. Food Chemistry, 122, 1076-1082.

13. Macheix JJ, Sapis JC, Fleuriet A (1991). Phenolic compounds and polyphenol oxidase in relation to browning in grapes and wines. CRC Crit. Rev. Food Sci. Nutr. 30:441-486.

14. Monagas M, Bartolomé B and Gomez-Cordoves C (2005). Updated knowledge about the presence of phenolic compounds in wine. Crit. Rev. Food Sci. Nutr. 45, 85-118.

15. Monagas M, Suárez R, Gómez-Cordovés C, Bartolomé B (2005). Simultaneous determination of nonanthocyanin phenolic compounds in red wines by HPLCDAD/ESI-MS. Am. Journal of Enology and Viticulture, 56, 139-147.

16. Moreno J, Peinado J and Peinado RA (2007). Antioxidant activity of musts from Pedro Ximénez grapes subjected to off-vine drying process. Food Chemistry, 107, 224-228.

17. ** OIV 2012, International oenological codex, edition 2012. Recueil des methodes internationales d'analyse des vins et des mouts. Office International de la Vigne et du vin, Paris

18. Puech JL, Feuillat F and Mosedale JR (1999). The tannins of oak heartwood: Structure, properties, and their influence on wine flavour. American Journal of Enology and Viticulture, 50(4), 469-478.

19. Rosso MD, Panighel A, Vedona AD, Stella L and Flamini R (2009). Changes in chemical composition of a red wine aged in acacia, cherry, chestnut, mulberry and oak wood barrels. Journal of Agricultural and Food Chemistry, 57, 1915-1920.

20. Singleton VL (1987). Oxygen with phenols and related reactions in musts, wines, and model systems: Observations and practical implications. American Journal of Enology and Viticulture, 38, 69-77.

21. Stevanato R, Fabris S and Momo F (2004). New enzymatic method for the determination of total phenolic content in tea and wine. Journal of Agricultural and Food Chemistry, 52, 6287-6293.

22. Timberlake CF and Bridle P (1976). Interactions between anthocyanins, phenolic compounds, and acetaldehyde and their significance in red wines. American Journal of Enology and Viticulture, 27, 97-105.

23. Vivas N and Glories Y (1996). Role of oak wood ellagitannins in the oxidation process of red wines during aging. Am. J. Enol. Vitic. 47, 103-107.

24. Zafrilla P, Morillas J, Mulero J, Cayuelas JM, MartínezCachá A and Pardo F (2003). Changes during storage in conventional and ecological wine: Phenolic content and antioxidant activity. Journal of Agricultural and Food Chemistry, 51, 4694-4700 